\title{
Resistivity Models of Pantar Island Geothermal System East Nusa Tenggara, Indonesia
}

\author{
Y.A. Taufan ${ }^{1, *}$, I. Syafri ${ }^{1}$, A.Agus Nur ${ }^{1}$, D. Risdianto ${ }^{2}$, A. Zarkasyi ${ }^{2}$, T.Rahadinata ${ }^{2}$, W. \\ Awaludin ${ }^{2}$ \\ ${ }^{1}$ Department of Geological Enginerring, Padjadjaran University, , Bandung, Indonesia. \\ ${ }^{2}$ Department Centre for Minerals, Coal, and Geothermal Resources, Geothermal Group, Bandung, Indonesia.
}

\author{
* Corresponding author: yoqie.taufan@gmail.com \\ Tel : +628179189958 \\ Received : June 5, 2020; Accepted : July 24, 2020 \\ DOI : 10.25299/jgeet.2020.5.3.5115
}

\begin{abstract}
The subsurface geological conditions of a geothermal system are vital objects to be considered in geothermal exploration. The Magnetotellurics survey was conducted to explore for geothermal potential in Pantar Island. This is to achieve deeper penetration compared to our previous study that adopted resistivity method to determine reservoir zones based on rock resistivity models. The difference in rock resistivity in geothermal systems provides subsurface geological information in the form of low resistivity that associated the clay cap zones (high conductive), the medium resistivity zones associated with the reservoir zones, and high resistivity associated with a heat source. The results of 2D and 3D models from MT data show that the low resistivity value $(<20 \Omega \mathrm{m})$ as a clay cover zones, this layer from the surface to -1000 meters. Medium resistivity values (20-100 $\Omega \mathrm{m}$ ) starting from depths -1000 meters to -2000 meters associated with reservoirs zones, high resistivity values (> $200 \Omega \mathrm{m})$ starting from depths of -2000 meters are considered as heat source from the Pantar geothermal system.
\end{abstract}

Keywords: Magnetotellurics, resistivity models, geothermal system

\section{Introduction}

\subsection{Background of Research}

Indonesia has a large geothermal potential in the world (Merry et al., 2017), with a potential resource of 11,073 MW and reserves of 17,506 MW (Ministry of Energy and Mineral Resources., 2017) but only a few regions have produced (Maryanto et al., 2017).

The existence of geothermal energy consists of exploration activities to find potential energy sources. Required geological conditions that have geothermal system criteria, this system is indicated by the presence of clay cover, reservoir where liquids accumulate, heat sources, geological structures that are generally in the form of fractures, and fluids that act to deliver heat from the reservoir to the surface. (Moeck, 2014) The existence of a geothermal system in an area will not exist if the components of the geothermal system are not met. (Carlson and Plumer, 2008). The existence of reservoir information is an important part of the next stage of geothermal exploration.

Geothermal energy is formed naturally through the interaction of rocks and heat flowing beneath the earth's surface (Zobin, 2017). The geothermal conditions require an effort to find energy potential as an exploration activity. Traditional geological methods have difficulty identifying geothermal reservoirs that are buried deep because they only depend on the availability of point measurements, including hot spots, and analysis of water samples. Geophysical methods with deep penetration for reservoir detection are the key to geothermal energy exploration (Lan Fang et al., 2016).
Geophysical investigation with gravity method and AMT (Audio-frequency Magnetotellurics) method for geothermal potential on Pantar Island was conducted in 2015. This investigation was aimed at finding out the geothermal system on Pantar Island (Figure 1). The results of the investigation with 2 (two) methods are still limited to the depth of subsurface geological information (Rahadinata and Taqodama, 2015).

Geophysical investigation using Magnetotellurics (MT) method was carried out as a follow-up. (Nainggolan et al., 2015). This method has the advantage of deeper penetration (Aboud, 2014) with better accuracy compared to previous investigations.

The MT method is one of the most widely used geophysical methods in geothermal exploration (Lowrie, 2012), (Reynolds, 2011) because of its ability to detect relatively deep subsurface conditions. This method is one of the passive geophysical exploration methods which record the magnitude of the earth's electromagnetic field (EM), in order to determine the subsurface geological conditions with resistivity and conductivity parameters (Bera and Rao, 2012).

Difference in rock resistivity geothermal systems can provide subsurface geology in the study area, including determining reservoir zones (Panjaitan, 2010).

The purpose of this research is to study the geothermal reservoirof Pantar Island, and obtain 2D \&3D subsurface models based on the resistivity parameters generated from Magnetotellurics (MT) which is continuation of the method from previous studies.

\subsection{Location}


The location of this research is in geothermal area, of Mount Sirung, Pantar Island. Located in Alor Regency, East Nusa Tenggara Province, Indonesia. Located at coordinates 9059000
- $9073000 \mathrm{mU}$ and 621000 - $633000 \mathrm{mT}$ on the UTM system, $51 \mathrm{~S}$ zone.

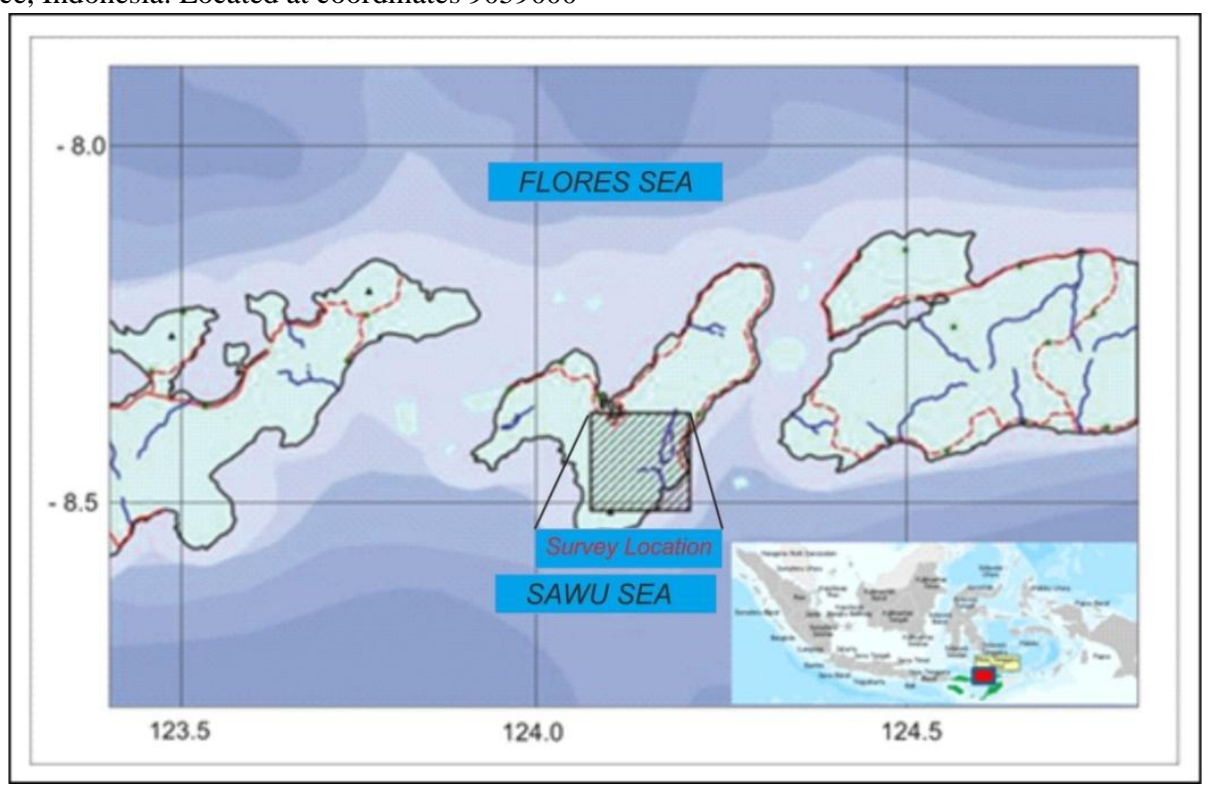

Fig 1. The Research Location, Pantar Island, East Nusa Tenggara, Indonesia (Adapted from Hadi and Kusnadi., 2015)

\subsection{Regional Geology}

The rocks that occupy the north and east coasts are sedimentary rocks, which are limestone reefs, in the middle there are the oldest rocks formed at the end of Tertiary namely Kongmewas rocks and Kalondama volcanic rocks with a geological structure directed north which separates the two old volcanic products. Volcanic products in the form of old Sirung products occupy the middle to the eastern part of Beang beach, while the Sirung pre-caldera formation is filled with Boyali volcanic products, and Mauta is in the south.

In the middle between the peaks of Sirung Tua and Boyali, a large explosion process occurs which produces pyroclastic and basal lava. The old Sirung pyroclastic product and the material that came out was the result of a large eruption which caused a mass vacuum in the middle to collapse and form the
Sirung caldera. Volcanic activity appears next to the collapsed caldera wall forming Sirung's lava body and outside the caldera forms Beang Hill. The young Sirava lava in the middle of the Sirung crater is the youngest product of the Sirung complex. The geological structure that developed in the field of investigation is dominated by the north-south direction relatively as a major internal fault. This pattern is related to the regional tectonic direction that is developing in the Pantar area (Figure 2).

In this area there are volcanic structure patterns such as caldera, allegedly formed by a massive eruption that exploded from the eruption of the Mount Sirung Complex resulting in a mass vacuum and collapsed to form a caldera and a crater. The volcanic structure pattern of Sirung volcanic caldera formed around the summit of Mount Sirung forms linear with diameters starting from $2 \mathrm{~km}$ (Hadi and Kusnadi, 2015).
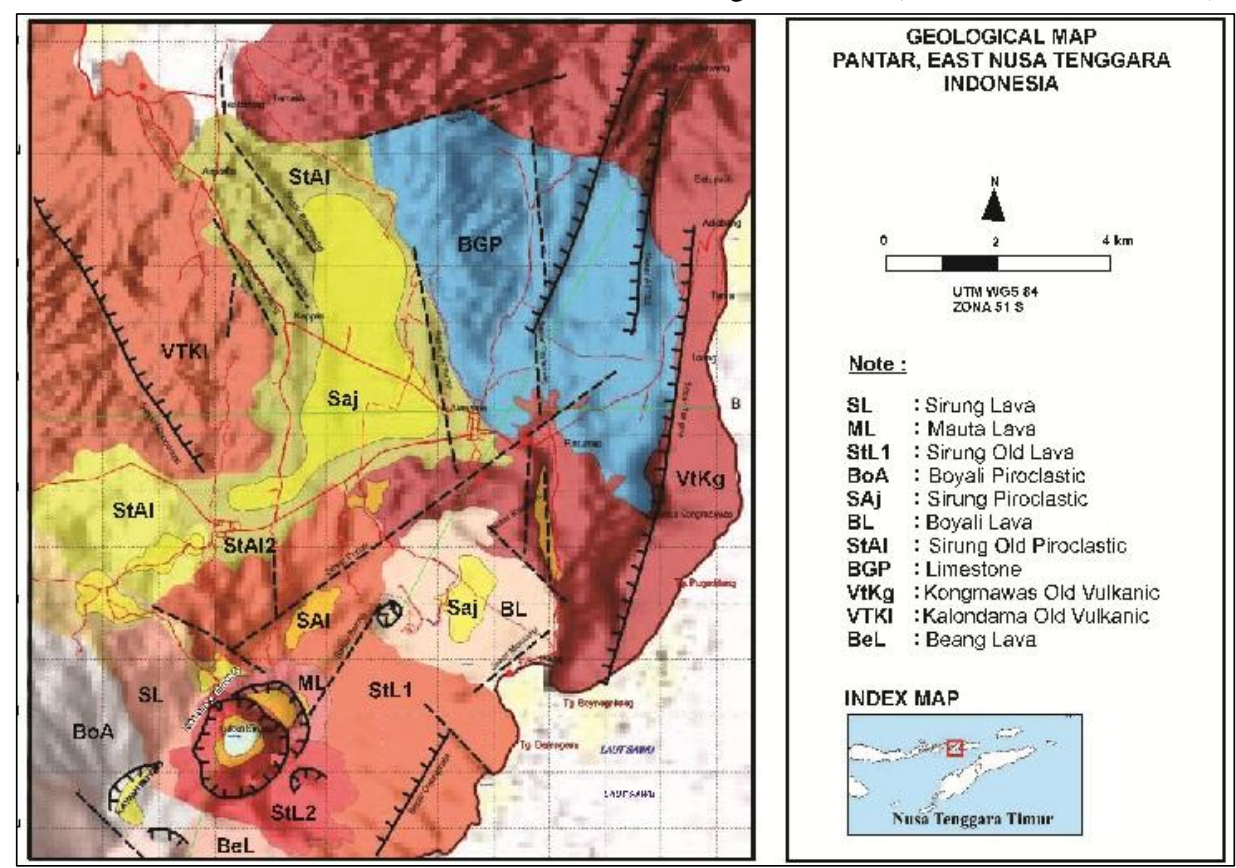

Fig 2. Geological Map of Research Location, Pantar Island, East Nusa Tenggara, Indonesia (Hadi and Kusnadi, 2015) 


\section{Method}

\subsection{Basic Theory of MT}

The electric-magnetic phenomenon affecting electrical properties (Unsworth, 2006), especially the conductivity of the medium (earth) can be exploited for exploration purposes using the MT method. This is done by simultaneously measuring variations in the electric field (E) and magnetic field $(\mathrm{H})$ as a function of time. Information about conductivity or resistivity contained in MT data can be obtained using the Maxwell equation (Telford et al., 1990) using a relatively simple model. MT measurement can produce resistivity information as a function of frequency and then can produce true resistivity to depth (m). MT measurements in this area have scattered observation points so that can be used as resistivity models on the west-east path. The results of the field data are then processed by Fourier transforming the data into a $2 \mathrm{D}$ inversion process, then visualizing the 3D model for analysis into subsurface geological information.

The differential form, Maxwell's equation (Telford et al., 1990) in the frequency domain can be written in the following equation:

$$
\begin{aligned}
& \nabla x E=-\frac{\partial B}{\partial t} \\
& \nabla x H=j+\frac{\partial D}{\partial t} \\
& \nabla \bullet D=q \\
& \nabla \bullet B=0
\end{aligned}
$$

$H$ is the magnetic intensity, $J$ is the current density, $E$ is the electric field, $B$ is the magnetic field induction, $D$ is the shift of electricity, and $q$ is the electric charge.
Equation (1a) is derived from Faraday's law which states that changes in magnetic flux cause an electric field with an electromotive force opposite to the variation of the magnetic flux caused by the electric field. Equation (1b) is a generalization of Ampere's theorem by calculating the law of conservation of charge enhanced by Maxwell. The equation states that the magnetic field will be generated as a result of the current density and fluctuating electric current movement. Equation (1c) states that Gauss's law is the transfer of electricity in a space in proportion to the density of the electric charge in that space. While equation (1d) which is identical to equation (1c) applies to magnetic fields, but in magnetic flux or induction there is no magnetic monopoly. Generally, the skin depth equation is written as inequation (2),

$$
\delta=500 \sqrt{\frac{1}{\sigma f}}=\sqrt{\frac{\rho}{f}}
$$

Equation (2) explains the value of skin depth is inversely proportional to frequency and directly proportional to wavelength. Every time in MT measurements in the field, the desired object is at a height that can be inside, then the EM waves needed are waves that have a small frequency or a large wavelength (Naidu, 2012)

\subsection{Research Stages}

The research method consists of data acquisition, data processing, and data interpretation. MT survey has been carried out in April2017. MT data acquisition has beencovering the area geothermal prospects. Location of the MT measurement is shown in black dots (Figure 3). Thedistance between measurement points is about $1-1.5 \mathrm{~km}$. The data processing, modeling, and interpretation ofobtained MT anomaly data have been carriedout at the Centre for Minerals, Coal, and Geothermal Resources, Geothermal Group, Bandung.

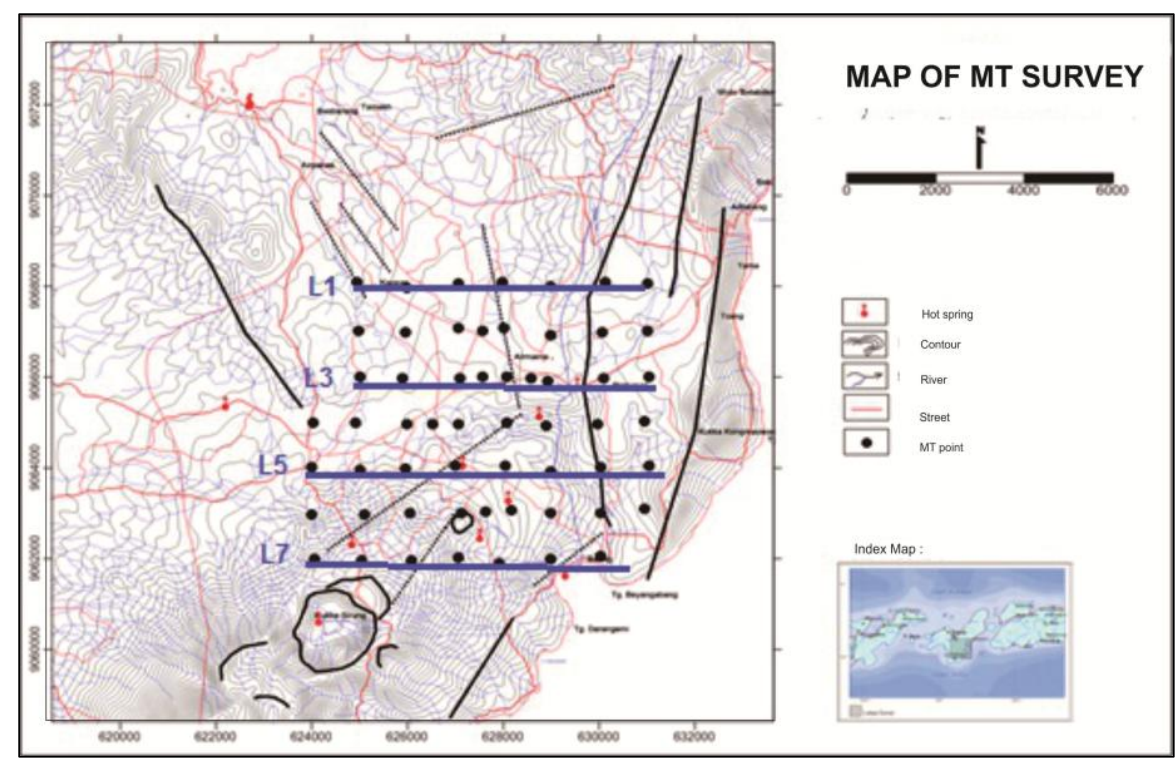

Fig 3. Research Location Map with 4lines MT (Adapted from Rahadinata and Taqodama, 2016)

Modeling for this research uses the inversion process, which is a modeling process by processing field data using mathematical and statistical parameters to obtain subsurface model information based on physical properties distribution (Meju, 1994). In the inversion process, an analysis of field measurement data is carried out by performing curve fitting between the mathematical model and the field measurement data. The purpose of the inversion process is to determine the physical parameters of subsurface rocks that were not previously known. 


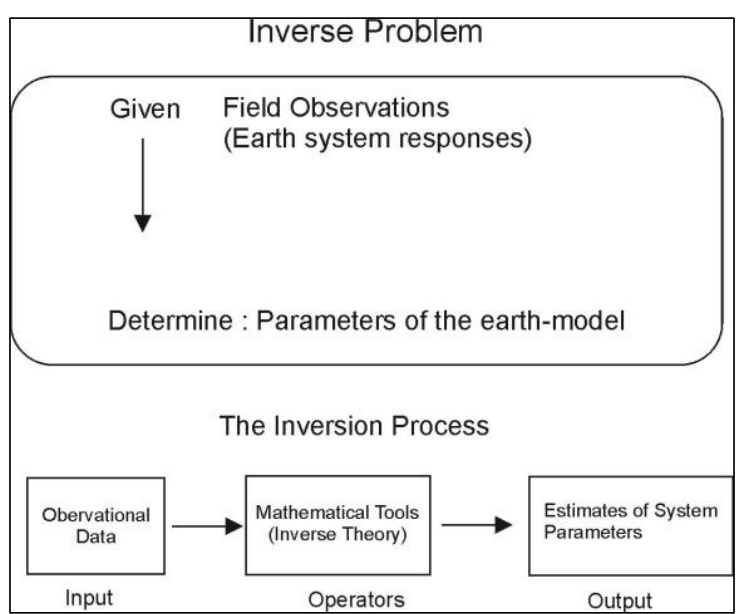

Fig 4. Inversion Modelling Flow (Meju, 1994)

\section{Result and Discussion}

The results which obtained in this research include the results of modeling and interpretation.

\subsection{Result of Resistivity Model}

The model results in the study area are designed to be representative of all regions that are thought to have geothermal prospects based on the results recommended by previous studies. Vertical models in the study area are displayed as many as 4 (four) line strajectories representing the study area. The results of the $2 \mathrm{D}$ and $3 \mathrm{D}$ models displayed provide combined information in the study area (Figure 3).

The results of this study obtain a subsurface model that is produced deeper than the previous resistivity method (Vozoff, 1991), thus providing heat source zone information on the geothermal system on Pantar Island. The resistivity distribution is displayed in various color scales. Blue indicates low resistivity (conductive), and red represents rocks with high resistivity values.

The zone of low value $\leq 20 \Omega \mathrm{m}$ from the surface to a depth of $-700 \mathrm{~m}$ and detected to a deeper depth that is a depth of -1000 $\mathrm{m}$ at other locations, is generally spread over most of the investigation area. Low zone around the manifestation of geothermal is thought to be related to hydrothermal activity in the form of alteration rocks which are found around the emergence of hot and hot water, tuff, breccia, polymic breccia, and pyroclastic. The results of the study also carried out a structural interpretation of the results of $2 \mathrm{D}$ resistivity model from this MT data. The 2D model is displayed in a vertical cross section that describes the vertical resistivity distribution of rocks (Singarimbun et al., 2017).

\subsection{Discussion}

\subsubsection{D Model}

The modelling results show rock resistivity values from $0 \Omega \mathrm{m}$ to $\geq 250 \Omega \mathrm{m}$. Line A (Figure 5), the uppermost layer with a low resistivity value $(0-20 \Omega \mathrm{m})$ shown by the blue layer, this layer continues from the surface to a depth of $-1000 \mathrm{~m}$ in the west and the east of the line, while in the middle of the line has a depth of $-750 \mathrm{~m}$. The low resistivity zone on this path is thought to be the response of the hydrothermal activity product rock in the form of alteration rocks and volcanic sedimentary rocks, this zone is thought to be a clay cap in this geothermal system (Weldeyohannes, 2018). The green-yellow, has a resistivity value of $20-100 \Omega \mathrm{m}$, this zone starts to appear at a depth of $-750 \mathrm{~m}$ which is in the middle of this path, in the west starts from a depth of $-1000 \mathrm{~m}$, and the east of this layer starts at a depth $-1200 \mathrm{~m}$. This layer is thought to be a transition zone between alteration rock and reservoir. Rock layers with moderate resistivity values are found along this path extending from west to east. Rock resistivity with a value of $20-100 \Omega \mathrm{m}$ starting from a depth of -1000 meters is thought to be a reservoir. This zone is thought to be the top of the reservoir of the Pantar Island geothermal system. Rock resistivity zones with high values (> $200 \Omega \mathrm{m}$ ) are shown by layers with a redpink color starting to appear at depths approaching $-2000 \mathrm{~m}$. This high resistivity zone is thought to be a heat-bearing rock from the Pantar Island geothermal system. (Parnadi et al., 2014)

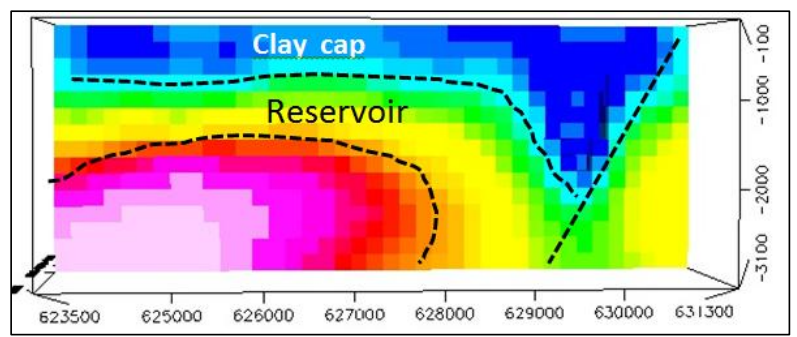

Fig 5 : 2D Model Resistivity Line A

The results (Figure 6) show a medium-high resistivity

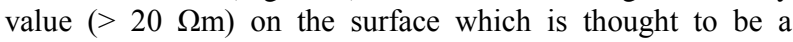
response from volcanic rock units in the form of lava. Underneath is a low resistivity value $(<10 \Omega \mathrm{m})$ that extends from the west to the east. The low resistivity (the blue layer) in the west is thought to be the response of alteration rocks resulting from hydrothermal, tuff, breccia, polymic breccia, and pyroclastic. While the low resistivity value in the east is thought to be the influence of sea water intrusion. To the east of this interesting zone there is a contrast value of resistivity, indicating the existence of a structure that is a barrier of the prospect zone of this area. This structure is a depiction of the Pintumas fault shown on the geological map (Hadi and Kusnadi, 2015).

The low resistivity value that is thought to be closely related to hydrothermal activity is in the middle of this passage and passes through several geothermal manifestations. The shape of the zone of low resistivity value in this section is assumed to be the closing zone of the geothermal system of the island of Pantar. After the low resistivity zone, there is a rock layer with a medium resistivity value $(20-100 \Omega \mathrm{m})$ from a depth of $-1000 \mathrm{~m}$ to $-2000 \mathrm{~m}$, which is assumed to be a reservoir in the form of a graben.

Rock resistivity zones with high values (> $200 \Omega \mathrm{m}$ ) are shown by layers with a red-pink color starting to appear at depths approaching $-2000 \mathrm{~m}$. This high resistivity zone is thought to be a heat source rock from the Pantar Island geothermal system.

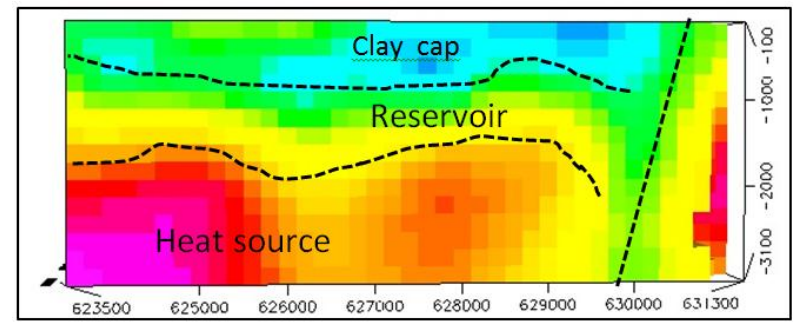

Fig 6. 2D Model Resistivity Line B

\subsubsection{D model}

The results from 3D model (Figure 7) show that the first layer of this area has rock resistivity with a resistivity value of $\leq 20 \Omega \mathrm{m}$ that occupies the entire investigation area at the surface to a depth of $-1000 \mathrm{~m}$. The low resistivity value in this area is thought to be the response of the alteration zone which 
is a product of hydrothermal activity and the response of tuff, breccia, polymic breccia, and pyroclastic breccia. It is suspected that this zone is a clay cap (zone in the Pantar geothermal system.

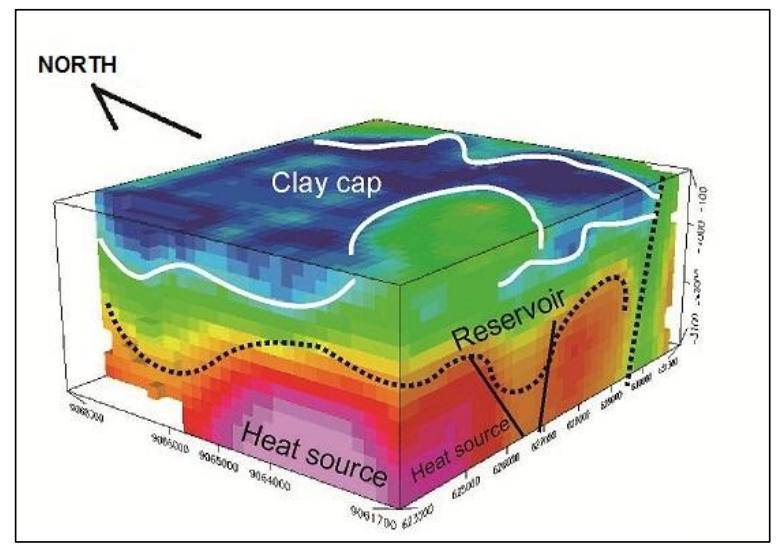

Fig 7. 3D Geothermal Syatem Based on Resistivity Model

At a depth of $-750 \mathrm{~m}$, a low-moderate resistivity value (20 - $50 \Omega \mathrm{m}$ ) is suspected. It is assumed that the low-moderate restivity value is a response from the lava lithology that spreads almost in most areas of investigation. This low-moderate resistivity value is thought to be a transition zone between the alter rock and the reservoir.

At a depth of -1000 meters the resistivity zone is expanding and forming a closed closure covering almost all of the manifestations around Mount Sirung. This medium resistivity value at a depth of $-1000 \mathrm{~m}$ is thought to be the peak of the reservoir of the Pantar Island geothermal system.

At depths of more than -1000 meters the expansion of the resistivity value of $20-100 \Omega \mathrm{m}$ is seen, this shows that the geothermal system in Pantar is located along the emergence of geothermal manifestations starting from Mount Sirung to the northeast to the Airmama heat. The rock zone with a resistivity of $20-100 \Omega \mathrm{m}$ at a depth of -1000 meters is thought to be a reservoir zone in the Pantar geothermal system. At depths of $1500 \mathrm{~m}$ the presence of rocks with moderate resistivity (20-100 $\Omega \mathrm{m}$ ) leads to groups of rocks with higher resistivity values (> $100 \Omega \mathrm{m})$.

In the east there is a low resistivity value, it is suspected that this is not related to hydrothermal activity, this low resistivity value is a response from limestone and also the response from sea water intrusion. This is due to its location in the eastern regions directly adjacent to the sea. At depths of $-2000 \mathrm{~m}$, visible rocks with a high resistivity value $>200 \Omega \mathrm{m}$ are located just below the medium resistivity value at the previous depth. This high resistivity value is thought to be the heat-bearing rock (heat source) of the Pantar Island geothermal system (Rahadinata and Taqodama, 2015).

\section{Conclusions}

The reservoir zones of the Pantar geothermal system are shown by resistivity of $20-100 \Omega \mathrm{m}$, this layer is at a depth of $1000 \mathrm{~m}$ to $-2000 \mathrm{~m}$ and in some areas began to appear at shallower depths. This reservoir zone is closed by clay cap with resistivity values $<20 \Omega \mathrm{m}$ which are considered as alteration, tuff, breccia, polymic breccia, and pyroclastic. The presence of geothermal fluid is suspected in this reservoir zone so that it becomes important information for the next exploration stage.

\section{Acknowledgements}

The authors thank the research team of the Centre for Coal, Minerals, and Geothermal Resources, the geothermal field group, for helping and authoring the writing of this paper.

\section{References}

Aboud, E., Saud, R., Asch, T., Aldamegh., K.,Mogren, S., 2014. Water Exploration using Magnetotelluric and Gravity Data Analysis; Wadi Nisah, Riyadh, Saudi Arabia. National Research Institute of Astronomy and Geophysics Journal 3, 184-191.

Bera, P., X Rao., C.K., 2012. Magnetotelluric Method: A Tool for Deep Crustal Study, $9^{\text {th }}$ Biennial International Conference \& Exposition on Petroleum Geophysics, Mumbai: Society of Petroleum Geophysicists India.

Carlson, D.H and Plumer, C..C., 2019. Physical Geology, $16^{\text {th }}$ Edition, Mc Graw Hill. New York,

Hadi, M.N., Kusnadi, D., 2015. Geological and Geochemical Survey, Pantar Geothermal Area, East Nusa Tenggara. PSDG, Bandung, Indonesia. (Text in Indonesian).

Lanfang, He., Chen, L., Dorji, X., Xi, X., Zhao., Chen, R., and Yao, H., 2016.Mapping the Geothermal System using AMT and MT in The Mapamyum (QP) field, Lake of Manasarovar, Southwestern Tibet. Energies Journal.

Lowrie., W., 2012. Fundamentals of Geophysics, Second Edition. Cambridge University Press.

Mary, RT., Armawi, A.,Hadna, A.H., Pitoyo, A.J., 2017. Geothermal is Treasures For Towards Energy Security. Journal Ketahanan Nasional. Indonesia23, 217-237. (Text in Indonesian)

Maryanto, S., Dewi, C.N., Syahra, V., Rachmansyah, A., Foster, J.H., Nadhir. A., Santoso, D.R., 2017. Magnetotelluric Geochemistry Investigations of Blawan Geothermal Field, East Java, Indonesia. Geosciences, DOI: 10.3390/geosciences70200417, (2) 41-50

Meju, A.M., 1994. Geophysical Data Analysis : Understanding Inverse Problem Theory and Practice. Society of Exploration Geophysicists (SEG).

Ministry of Energy and Minerals Resources. Indonesia Geothermal Potential.,2017. First Edition.

Moeck. I.S., 2014. Catalog of Geothermal Play Types Based on Geologic Controls. Renewable and Sustainable Energy Reviews 37, 867-882.

Naidu, G.D., 2012. Deep Crustal Structure of The SonNarmada-Tapti Lineament, Central India. Springer, 1335 .

Nainggolan, S.S., Sastranegara, R.M.T., Raharjo, I.B., 2015. Volcanic Neck of Mount Iyang Argopuro Revealed from Gravity Study. Proceedings WorldGeothermal Congress, 19-25 April 2015, Melbourne, Australia.

Panjaitan, S., 2010.Geology of Ulubelu Tanggamus Geothermal Area, NorthLampung Based on Magnetotelluric (MT) Method Analysis. Jurnal Geologi dan Sumberdaya Mineral, Vol. 20, No. 2 Badan Geologi. Indonesia 2, 69-91. (Text in Indonesian)

Parkinson., W.D., 1983.Introduction to Geomagnetism. Scotish Academic Press, 220-346.

Parnadi, W.W., Widodo., Savitri, R.W., Zakarsyi, A.. 2014. Magnetotelluric Investigations in The Way Umpu Geothermal Prospect Area, Lampung Province, Indonesia. International Journal of Technology 3, 227241.

Reynolds., J.M., 2011. An Introduction to Applied and Environmental Geophysics Second Edition, United Kingdom. John Wiley \& Sons Ltd.

Singarimbun, A., Gaffar, E. Z., Tofani., P., 2017.Modeling of Reservoir Structure by Using Magnetotelluric Method in The Area of Mt. Argopuro, East Java, Indonesia.Journal. Eng. Technol. Sci 49, 833-847.

Sircar, A., Dhale, S., Shah, M., Vaidya, D., Yaday, K., 2017.2D and 3D Magnetotelluric Survey for Geothermal Reservoir Identification. Drilling and Exploration World (DEW) Journal, Dehradun, India, 61-75. 
Telford, W.M., Geldart, L.P.,. Sheriff, RE.,1990. Applied Geophysics Second Edition, New York, United States. Cambridge University Press.

Rahadinata, T., Taqodama, I., 2015. Gravity and AudioMagnetotelluric (AMT) Survey, Pantar Geothermal Area, East Nusa Tenggara”. PSDG. Bandung. Indonesia. (Text in Indonesian).

Unsworth.,M., 2006. Electromagnetic and Potential Field Method Geophysics. University of Alberta.

Vozoff, K., 1991. The Magnetotelluric method in Nabighian, Electromagnetic Method in Applied geophysics, vol. II, part B: Society of Exploration Geophysicists. Tulsa
Oklahoma, 641-711.

Weldeyohannes., H., 2018.Magnetotelluric Methods in Geothermal Exploration at Aluto Langano Ethiopia.Proceedings, $7^{\text {th }}$ African Rift Geothermal Conference Kigali, Rwanda.

Zobin, V.M., 2017. Introduction to Volcanic Seismology (Third Edition). Elsevier.

(C) (†) () $\odot 2020$ Journal of Geoscience, Engineering, EY SA 1 Environment and Technology. All rights reserved. This the CC BY-SA License (http://creativecommons.org/licenses/by-sa/4.0/). 